\title{
EDITORIAL
}

\section{New aesthetics and practice in experimental electronic music}

Most research and academic writing about electronic and electroacoustic music is focused on music produced within academic communities - an inward-looking dynamic. The theme of Organised Sound 13(1) was established to explore work that exists outside this domain, work not supported by the academic economy. What is this work? From 1994, a body of works emerged, Oval's Systemisch (1994, Thrill Jockey/Mille Plateaux), Ikeda's +/- (1996, Touch) and Autechre's Grantz Graf (2002, Warp) to identify a few. These heralded new aesthetic approaches to experimental music, new formations of technologies, and more.

'Electronica', 'post-digital', 'microsound', 'glitch', or one of many other descriptions of sub-genres have been proposed, used, defined and re-defined to quantify the field. Yet all these classifications for new approaches to computer music are problematic in some respect; many are misrepresentations or, in fact, meaningless terms, often revealing more about authors' intentions than their subject. Not surprisingly, many of the leading figures working outside our academic tradition reject the notion of single, unified genres, so why should academic debate seek to impose this? Why should we find a single term to circumscribe the whole of experimental electronic and computer musics simply because they don't follow a lineage from high modernism or define their raison d'être from academic discourse?

The research group 'New Aesthetics in Computer Music' (of which I am Principal Investigator) has recently coined the terms oppositional and independent practice (originally proposed by Mark Fell) to describe the field. This relates to both the independence of sound artists and composers who work outside academe, and the idea that much work in this field is in opposition to received musical aesthetics. Such practice is not primarily influenced by Schaeffer, or spectromorphology, or constructs derived from instrumental music or structuralist approaches to the manipulation of sound and audio parameters. Oppositional and independent are also terms which have resonance with artists' approaches to methods of creation and the dissemination of their work. In fact, the work of many artists in this field has little in common, except for similarities in their combination of artistic, economic and cultural practice. This combination is as likely to be a distinguishing factor as any description of audio content or audio production method.

I was pleased to see that Rolf Grossmann used the phrase 'the technological transformation of music' in his article for this issue - music has changed. The works that are being performed in venues, festivals and galleries throughout the world and which are being distributed via new communications technologies are not the same as the electroacoustic and electronic works of the latter twentieth century. And why would they be. Almost everything touched by the development of technology has changed in the contemporary world, and the fundamental use, creation, aesthetics, reception, consumption and cultural context of music has shifted. In fact, music may now be a problematic term for some twenty-first-century sound artists.

My attempt to define this field in the call for submissions was originally by example - a list of indicative artists, performers and composers. In addition, I listed suggestions for the focus of articles:

- audio works, albums or sound installations,

- the work of individual composers and sound artists,

- audio works with common aesthetic foundations,

- music dissemination and distribution methods,

- aspects of live performance and music presentation,

- discussions of contemporary philosophical thought relating to music and sound art.

I am pleased to say that the collection of writings which resulted from the submission and review process lie within these areas.

Rolf Grossmann reviews the current influence of technology on music production, along with recent changes in music performance and consumption brought about by the adoption of technological means; highlighting a shift in music, or perhaps the rupture of contemporary sound art from many musical traditions. $\mathrm{He}$ forecasts even more extreme changes in the future.

The notion of influence can often be at the foreground of musical discourse. In an intriguing and thought-provoking article, Paul Hegarty considers the possibility that within extreme forms of contemporary experimental music, such as noise-based genres, the notion of influence cannot exist. 
Daniella Cascella surveys the work of one of the twenty-first century's most influential audio artists Carl Micheal von Hausswolff. Her article discusses his audio work and other artistic outputs for different media (and minds). His work and live performances illustrate the immense power of pure sound. I'm delighted that it has been possible to include excerpts of von Hausswolff's work on the Volume 13 DVD, and would like to thank him for allowing us to reproduce sections from some of his audio works.

One of the most significant centres of artistic activity in contemporary electronic music is Germany's raster noton label. Adam Collis looks at the work of one of their artists Carsten Nicolai, whose visual artwork has featured previously in the pages of Organised Sound. Collis' article focuses on Nicolai's use of noise derived from a variety of electronic systems.

The distinction between contemporary experimental musics and popular genres are further illustrated in the difference between Paul Hegarty's description of noninfluence and Thomas Shave's consideration of hybrid musical forms. Thomas Shave presents a new approach to the analysis of popular music, Communicative Contract Analysis. This method is based upon the application of semiotic models to extract references in hybrid musical forms of popular music.

Sound installation and practical considerations relating to the use of sound materials for public art installations in populated areas are discussed by Sven Anderson. The adoption of techniques similar to those used within what has been termed the 'microsound' genre are described in the context of public art and the sound environments of public spaces.

Outside the theme of this issue, Stephen F. Lilly describes the implementation of a synthesis technique using functional iteration and illustrates the characteristics of this method with a series of his own compositions.

Having spent some time away from the day-to-day processes of editing journals (I stepped down as a coeditor of Organised Sound in 2003), I was struck on my return as a guest editor by how journals are able to represent and explore their themes. The submission policies, requirement to produce journals with a particular page count in addition to the complexities of the call for works process, independent refereeing, feedback to authors and consequent paper development all combine to establish a system that has a significant effect on what appears in print, as one might expect. The best laid plans, promises and designs can often flounder because of time pressures on contributing authors by their employers, their ability to sustain the act of writing an article (financially) and unforeseen circumstances which can be encountered through the long compilation process. The duty of the editor to find appropriate and rigorous referees for each submission can also be difficult, particularly in a highly specialised area, and clearly has a large influence on what appears in print. Each aspect of this process determines who is able to publish and what it is possible to publish. Finding ways to open up this system to facilitate contributions by musical professionals or professional critical commentators may be a fruitful way for publishers to expand the readership of more specialist journals beyond small academic communities. In scientific disciplines, research supported by large corporations often fertilises debate and discussion in journals. Music, and particularly experimental forms, can't sustain corporations, but professional research activity does take place and commercial activity does require artistic innovation. Unfortunately, for economic reasons, much of this innovation is excluded from music journals.

As a consequence of the negotiation with the systems and processes of the journal, the resulting issue is not a 'curated' collection of writings, but one that results from an interaction with the journal's systems.

I would like to thank all the referees who looked at submissions for this issue of Organised Sound for their diligent and careful work, which was often in more precise and considered detail than I could have hoped for. This is the unseen work of the journal and its supporters, since the most demanding and difficult judgements are often related to those articles which don't appear in print.

A number of papers which did not make it into this issue exhibited common performative traits which I have seen in a number of recent articles. While many authors might be inspired to write as simply and clearly as possible, to raise simple points and avoid the linguistic complications which can emerge from the language games of specialist communities, a significant proportion of contemporary academic writing on electroacoustic music, much of which is featured in the pages of Organised Sound, seems to me to be taking an opposite tack.

Often, the impenetrable linguistic constructions which describe electroacoustic music appear designed to promote a rhetoric or to disguise ill-conceived, confused ideas about music with inappropriate manipulations of metaphor. Texts about electroacoustic music generated by other texts about electroacoustic music, ad infinitum.

I regularly read extended metaphors coined to describe and analyse electronic music and continue to see myths, which have been perpetuated for as long as I can remember, as the foundation of many discussions (I paraphrase): 'any sound imaginable can be created by computers, there are an infinite number of possibilities', 'the computer is a sonic-prosthetic', 'it is important that the microstructure of the work is reflected in the macrostructure' and many other similar statements with which I could fill an issue of the journal.

What do these statements mean? What and moreover who are they for? Should we question traditional 
rhetorics or accept them as unassailable musical truths? Are we representing the body of research and practical experiences amassed in the field over sixty years or revisiting the same territories? A careful analysis of the logical construction of many descriptions unfortunately reveals little about music per se.

Additionally, the endless discussion of the implications of Schaeffer's work, spectromorphology, and rather circuitous discussions of new terminologies for surround sound, musical gesture, ever more complex categorisations of sound accompanied by correspondingly complex diagrammatic representations of (and I open an issue of the journal at a random page, then seek the nearest categorisation) 'sustained, impulse, iterated, composite and accumulated sound'. Are we lacking definitions of these terms? (No) Once again, many discussions appear to reveal more about their authors than their subject.

The dreams of the past prompted visions of future electronic musics, but our considerable experience has revealed different realities. An 'infinite number of possibilities' maybe - given infinite computing power, infinite programming time, infinite exploration of the programs and a brain that can imagine the unimaginable result of this combination of infinite possibilities none of these things are possible in the world.

I would like to end this editorial comment with a simple call for a future discourse on electronic music that can provide accurate and factual descriptions of sounds and music in the context of contemporary cultures, economies and philosophies, particularly in relation to the function of music and of musical research within the societies and communities who support it.

Dr Tony Myatt

Director, Music Research Centre

Department of Music

University of York

UK

E-mail: am12@york.ac.uk

I'd like to thank Leigh Landy and Bharti Mistry from the Organised Sound office for their help and support during the preparation of this issue.

Issue 13(1) of Organised Sound includes a non-thematic contribution, 'Contemporary trends in the use of space in electroacoustic music' by Felipe Otondo, and a review by Mathew Adkins of Andrew R. Brown's recent book, Computers in Music Education: Amplifying musicality. The journal welcomes contributions on any topic related to electroacoustic music studies in its broadest sense and encourages the review of books related to this area. Authors are welcome to submit their work at any time; reviewers interested in writing about a recent publication should contact the journal directly, both at os@dmu.ac.uk

Leigh Landy (Editor) 